\title{
ÁRBOLES Y ARBUSTOS DE LA PRIMERA CUADRA DE LA ALAMEDA BOLOGNESI: ESTUDIO BIOSISTEMÁTICO
}

\author{
TREES AND SHRUBS OF THE FIRST BLOCK OF ALAMEDA BOLOGNESI: \\ BIOSYSTEMATIC STUDY
}

\author{
${ }^{1}$ Rosario Zegarra Zegarra ; ${ }^{2}$ Nelly Arévalo Solsol; ${ }^{3}$ Vanessa Chávez Zegarra
}

\begin{abstract}
RESUMEN
En la primera cuadra de la Avenida Bolognesi de la ciudad de Tacna, existe una serie de especies arbóreas, muy delicadas, unicas y especiales. Probablemente hayan sido sembradas por personas extranjeras inmigrantes, o por alguien que gustaba de la belleza del arte de la Jardinería. En el presente estudio se pretende motivar el cuidado de dichas especies, porque hace unos años atrás existian otras pero que han sido taladas. Las que hoy tenemos hay que protegerlas y preservarlas para la posteridad. Este trabajo tiene como objetivo conocer las especies arbóreas y arbustivas existentes, en dicho lugar. Se describen 19 especies ornamentales correspondientes a 16 familias de especies botánicas.
\end{abstract}

Palabras clave: Alameda Bolognesi, Jardineria, árbol, arbusto, ornamental, familia.

\section{ABSTRACT}

In the first block of Avenida Bolognesi in Tacna city, there are a number of tree species, very delicate, unique and special. They have probably been planted by foreign immigrants, or someone who liked the beauty of the art of gardening. This article is intended to take care of these species, because a few years ago there have been others that have been cleared. So that no one has to look after, preserve, protect and preserve them for posterity. This research aims to determine the tree and shrub species existing in this place. Nineteen ornamental species corresponding to 16 families of botanical species are described.

Key Words: Alameda Bolognesi, Gardening, tree, shrub, ornamental, family.

\section{INTRODUCCIÓN}

Con el paso del tiempo, el modo de vida del hombre varió. Lo que en un principio fue necesidad pura y simple para procesar alimento, lo cual llevó al desarrollo de la agricultura, aquella necesidad cambió, pues se convirtió en deseo estético e intelectualmente sofisticado, al rodearse de flores y de verdor. Si bien la agricultura está destinada a la nutrición del cuerpo del hombre, las especies ornamentales en cambio, constituyen en el alimento del espíritu.

Árboles y arbustos ornamentales son aquellos que aportan un elemento estético al paisaje, a la ciudad o a la vivienda.

Entre las características de los árboles ornamentales se consideran el tamaño, corteza del tronco, forma, color, floración y coloración de los frutos.

Entre las cualidades estéticas de los arbustos ornamentales se encuentran las formas que presentan, la coloración del follaje, las flores, los frutos y el aroma que exhalan.

Los árboles, arbustos y otras plantas ornamentales tienen un gran impacto ambiental. Se considera que la jardinería ambiental es también una de las maneras más efectivas y económicas de mejorar y mantener la calidad del medio ambiente.

En nuestra ciudad, como en las grandes ciudades de la costa, especialmente aquellas que crecen aceleradamente, es un problema la insuficiencia de áreas verdes (parques, jardines), que tienen la función de purificar el aire, proporcionar recreo para la población y educar a la juventud, fomentando la cultura.

La ciudad de Tacna, se caracteriza por sus hermosas áreas verdes que son motivo de admiración de propios y extraños. Existen muchas especies de plantas que las observamos en todos los jardines y avenidas. En la primera cuadra de la Avenida Bolognesi se conservan especies añosas que son de espectacular belleza por sus características botánicas.

Estos hermosos ejemplares constituirian la base, con la que se, podría iniciar un Jardín Botánico, como en una ocasión precisara Fernández de Córdova (2003)

\section{Objetivo General}

Caracterizar y sistematizar las familias de plantas 
que se hallan representadas en la primera cuadra de la Avenida Bolognesi.

\section{Objetivos Específicos} Pinophyta

Conocer las especies pertenecientes a la División Magnoliophyta

Reconocer que especies pertenecen a la División

\section{MATERIALES Y MÉTODOS}

\section{Zona de estudio}

Se ha estudiado únicamente la primera cuadra de la avenida Bolognesi. Alli se encuentran especies que no se observan en otros jardines, ni en avenidas de la ciudad. Algunas de ellas son únicas.

Metodologia.-Se procedió de la siguiente manera:

- Colección de las especies: De cada especie se tomaron ramas con hojas, flores y frutos. Luego para mejor estudio se procesó los ejemplares.

- Identificación de especies: La identificación taxonómica de las especies se realizó en base a literatura especializada, haciendo uso de claves y estudios taxonómicos.

\section{RESULTADOS Y DISCUSIÓN}

Se describen 19 especies de árboles y arbustos, de los cuales, 9 son de origen americano y 10 son exóticos.

Dos especies pertenecen a la División Pinophytas y 17 a las Magnoliophytas.

Entre los caracteres de valor diagnóstico utilizados para el reconocimiento de las especies, tenemos dos: el carácter vegetativo, en el que se considera la disposición y la morfología de la hoja; y el carácter reproductivo comprende los caracteres florales que son los más relevantes.

\section{Tratamiento Sistemático y Características Botánicas}

\section{A. División Pinophyta}

\section{Familia Araucariaceae}

Araucaria beteropbylla (Salisb.) Franco "Pino estrella"

Árbol de gran porte, con la copa piramidal y la ramificación verticilada. Su corteza se exfolia en pequeñas escamas.

Hojas jóvenes alesnadas y erectas de 7 a $18 \mathrm{~mm}$ de longitud. Hojas definitivas alesnadas de 6 a $8 \mathrm{~mm}$ de longitud.

Flores masculinas reunidas en amentos rojizos. Conos femeninos grandes y ovoidales, de 5 a $10 \mathrm{~cm}$ de longitud, con escamas ovuliferas espiraladas e imbricadas. Semillas de 3 a $4 \mathrm{~cm}$, uniovuladas, cuneiformes, con un pequeño mucrón terminal y dos alas.

Es la especie más alta de la ciudad de Tacna y oriunda de la isla de Norfolk, al este de Australia.

\section{Familia Cupressaceae}

Zegarra R. et at,, Árboles y arbustos de la primera cuadra de la Alameda Bolognesi: Estudio Biosistemático

\section{Cupressus macrocarpa Hartw. "Ciprés común"}

Árbol de copa piramidal, con ramificación ascendente. Presenta una corteza gris oscura y agrietada, formando placas de color pardo gris.

Hojas escamiformes, gruesas, de color verde oscuro, con olor a limón o mandarina.

Amentos masculinos cortos, terminales de color amarillo. Conos subglobosos de 25 a $35 \mathrm{~mm}$ de diámetro, color marrón rojizo y gris en la madurez, formados por 8 a 12 escamas ovuliferas. Contienen numerosas semillas de ala estrecha.

Especie nativa de Monterrey en California.

\section{B. División Magnoliophyta}

\section{b.1. Clase Magnoliopsida}

\section{Familia Anacardiaceae}

Schinus terebintbifolius Raddi "Molle hawaiano"

Árbol perennifolio, copa frondosa y ramificación muy extendida.

Presenta hojas compuestas imparipinnadas, con 5 a 7 pares de foliolos enteros, lanceolados de 2,5 a $4 \mathrm{~cm}$ de longitud.

Son de inflorescencia en los racimos axilares

Sus flores son blanquecinas. Las masculinas tienen diez estambres; las femeninas diez estaminodios y tres estilos.

Fruto drupáceo, esférico, de color rojizo.

Nativo de Sudamérica

\section{Familia Apocynaceae}

Nerium oleander L. "Laurelrosa"

Arbusto o árbol pequeño, laticífero, perennifolio, muy ramificado.

Hojas simples, verticiladas, generalmente en verticilos de a 3 , coriáceas, oblongo-lanceoladas, enteras, de 6 a $12 \mathrm{~cm}$ de longitud, de un color verde grisáceas.

Las flores aparecen reunidas en cimas terminales. Son de colores blancas o rosadas, de 5 a $8 \mathrm{~cm}$ de diámetro.

El fruto en folículo, oblongo, liso, mide de 8 a 18 $\mathrm{cm}$ de longitud. Las semillas recubiertas con un penacho de pelos.

La floración se da desde la primavera hasta otoño.

Nativa de la cuenca del Mediterráneo.

\section{Familia Bignoniaceae}

Jacaranda acutifolia H.B.K. "Jacarandá" simpódica.

Árbol caducifolio de gran porte y de ramificación

Sus hojas compuestas de 6 a 8 pares de pinnas, con los foliolos angostos, acuminados y enteros.

Inflorescencia: Racimos terminales de 25 a $30 \mathrm{~cm}$ 
de longitud.

Tiene flores hermafroditas, cigomorfas. Corola azul-violáceo, tubular-acampanadas.

El fruto es una cápsula elipsoidea, muy comprimida, castaña. Semillas planas y aladas.

Florece en primavera y es oriunda de Sudamérica

\section{Familia Euphorbiaceae}

Eupborbia pulcherrima Willd ex Klotzch "Cardenal-Corona del Inca-Flor de Navidad"

Especie arbustiva, laticífera, muy ramificada, ramas fistulosas.

Hojas simples alternas, aovado-elípticas, agudas, enteras o sinuadas de $10-15 \mathrm{~cm}$ de longitud.

Inflorescencia: Ramificada y formada por numerosos ciatos verdosos, con un gran nectario amarillo, rodeados por vistosos y grandes hipsófilos de color rojo o salmón.

Flores unisexuales.

Fruto: Tricoco

Nativa de Méjico y América central.

\section{Familia Fabaceae}

\section{Acacia visco Lor.ap.Grisebach "Vilca"}

Especie caducifolia, de tamaño mediano a grande, de 3 a $8 \mathrm{~m}$ de altura, inerme, de copa extendida y corteza de color castaño claro o rojiza.

Las hojas compuestas bipinnadas son de color verde claro, con 4 a 18 pares de pinnas, de pinnulas pequeñas $y$ acuminadas.

Inflorescencia: En falsos capítulos esféricos, amarillo pálidos, fasciculados de 1 a 5 por axila, sostenidos por pedúnculos de $1,5 \mathrm{a} 4 \mathrm{~cm}$ de longitud.

Flores bisexuales, actinomorfas, cáliz y corola pentámeros tubulares, de color amarillo.

Fruto en legumbre o vaina apergaminada, aplanada, dehiscente, de 7 a $14 \mathrm{~cm}$ de longitud. Semillas en número de 6 a 8 circulares y planas.

Florece en primavera.

Oriunda de América del Sur.

\section{Familia Fagaceae}

\section{Quercusilex L. "Encina"}

Árbol perennifolio de gran talla, corteza dura, gruesa, de color gris, agrietada, hojas simples, alternas, coriáceas, oblongo-lanceoladas, de 2 a $9 \mathrm{~cm}$ de longitud, margen aserrado o dentado-espinoso cuando están tiernas; las hojas adultas son enteras o dentadas. Haz verde oscuro; envés verde pálido.

Especie monoica. Flores masculinas reunidas en amentos de color amarillo, de 3 a $5 \mathrm{~cm}$ de longitud. Flores femeninas solitarias o en corto número.

Fruto: Bellota oblongo-cilindrica, el aquenio descansa en una cúpula leñosa, variable de forma y tamaño.
Nativa del Mediterráneo.

Quercus roburL. "Roble"

Árbol caducifolio, tiene la corteza gris, lisa, y se resquebraja con la edad.

Hojas simples alternas, pinnatilobadas, de 5 a 15 $\mathrm{cm}$ de longitud. Haz verde oscuro, envés verde claro.

Especie monoica. Flores masculinas con amentos aislados, de 5 a $10 \mathrm{~cm}$ de longitud. Flores femeninas en grupos de 2 a 3 largamente pedunculadas.

Bellotas oblongas de 2 a $4 \mathrm{~cm}$ de longitud, deprimidas en el ápice y la cúpula con brácteas fuertemente imbricadas.

\section{Nativo del Mediterráneo}

\section{Quercus suberL."Alcornoque"}

Árbol perennifolio de copa irregular, corteza provista de una gruesa capa corchosa.

Hojas simples, alternas, coriáceas, obovadasoblongas, de 3 a $7 \mathrm{~cm}$ de longitud, borde dentado y generalmente menos de siete pares de nervaduras.

Especie monoica. Los amentos masculinos tienen numerosas flores estaminadas, de 4 a $8 \mathrm{~cm}$ de longitud. Las flores femeninas están aisladas o en pequeños grupos.

Bellotas de 2 a $4,5 \mathrm{~cm}$ de longitud, de forma ovoide-oblongas, con la cúpula acampanada.

Oriunda del Mediterráneo.

\section{Familia Malvaceae}

\section{Hibiscus rosasinensis L. Cucarda-Rosa de la China"}

Arbusto, muy ramificado, glabro o subglabro.

Tiene hojas simples, alternas, aovadas, aserradas, de 6 a $15 \mathrm{~cm}$ de longitud.

Flores solitarias axilares, pedunculadas. Calículo conformado por 3 a 7 brácteas linear-lanceoladas. Pétalos de variados colores, predominando el rojo. Estambres monadelfos, formando una columna estaminal. Ovario súpero.

Fruto capsular, ovoide.

Nativa de China.

Es el arbusto más común, con flores de color rojo o amarillo-anaranjado.

\section{Familia Myrtaceae}

\section{Myrtus communis L "Arrayán"}

Arbusto aromático, perennifolio, de follaje compacto, muy ramificado.

Hojas simples, opuestas, coriáceas, aovadas o lanceoladas, de color verde oscuro en el haz y verde claro en el envés, mide entre 2 a $5 \mathrm{~cm}$ de longitud.

Flores solitarias axilares, pedunculadas, con cinco sépalos y cinco pétalos, de 1 a $2 \mathrm{~cm}$ de diámetro, de estambres numerosos exertos y ovario ínfero.

Fruto: Baya de forma esférica, negra azulada al 
madurar, de 1 a $1,5 \mathrm{~cm}$ de diámetro. Contiene numerosas semillas

Nativa de Europa meridional y norte de África.

\section{Familia Nyctaginaceae}

Bongaimillea spectabilis Willd. "Buganvila"

Arbusto con espinas caulinares.

Hojas simples, alternas, glabras o pubescentes, aovadas, de 5 a $7,5 \mathrm{~cm}$ de longitud.

Inflorescencia: Cimas trifloras, protegidas por tres hipsófilos de color púrpura, generalmente, las cimas son solitarias o paniculadas. Flores con perianto de color blanco lobulado, en su parte superior. Tiene 7 a 8 estambres. Ovario súpero.

Fruto anguloso rodeado por el tubo del perianto.

Oriunda de América (Brasil)

Florece en invierno, primavera.

Es la especic cuyas brácteas púrpuras símbolizan a nuestra ciudad, en la fiesta de Reincorporación a la Patria, el 28 de agosto.

\section{Familia Proteaceae}

Grevillea robusta A.Cunn "Roble sedoso" m de altura.

Árbol de gran porte, copa piramidal, mide hasta 20

Hojas pinnatifidas, coriáceas, haz verde oscuro, envés plateado, de 15 a $20 \mathrm{~cm}$ de longitud.

Inflorescencia: Tiene flores actinomorfas, hermafroditas. Perianto de 4 sépalos libres y 4 estambres. Ovario súpero.

Fruto: Folículo leñoso y oscuro.

Nativa de Australia.

Florece en primavera y verano.

Es la especie de la Clase Magnoliopsida más alta de la Alameda Bolognesi.

\section{Familia Phytolaccaceae}

Phytolacca dioica $\mathrm{L}$. "Ombú"

Especie dioica, tronco muy desarrollado en la base.

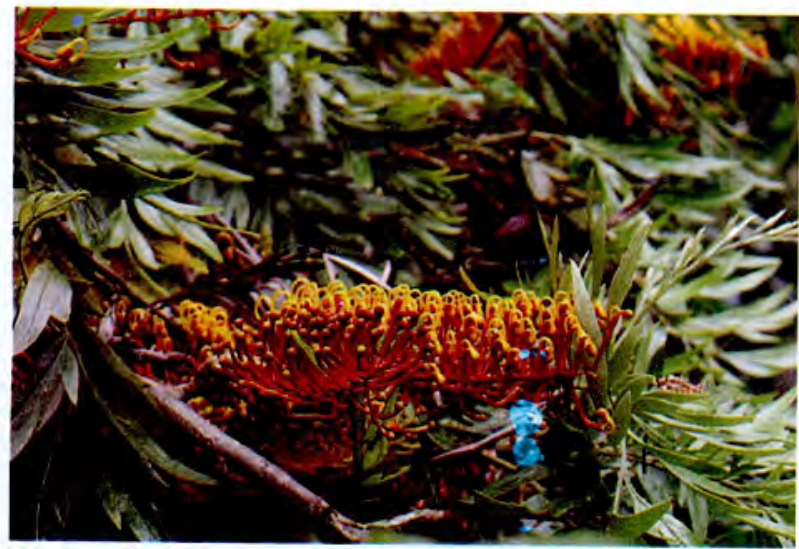

Figura N01. Grevillea robusta "Roble Sedoso"

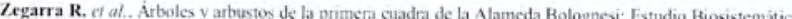

Copa globosa.

Presenta hojas simples, alternas, elípticas u oblongas, de 10 a $15 \mathrm{~cm}$ de longitud.

Flores masculinas, reunidas en racimos de color blanco. Perianto de 4 a 5 sépalos. Estambres numerosos. Flores femeninas con el gineceo súpero, con muchos carpelos uniovulados

Fruto en baya, de color verde y semillas negras.

Nativa de América del Sur (Nor este de Argentina).

Especie única. No se ve en otros lugares de la ciudad.

\section{Familia Solanaceae}

Brugmansia candida Pers. "Floripondio"

Árbol pequeño, siempre verde, con ramas suavemente pubescentes.

Hojas simples, alternas, elipticas u ovoides, margen entero, penninervias, base asimétrica, verde grisáceo y tomentosas de 10 a $20 \mathrm{~cm}$ de longitud.

Flores solitarias axilares y colgantes. Cáliz tubuloso y longitudinalmente hendido. Corola infundibiliforme, fraganciosa de color blanco. Tiene cinco estambres epipétalos inclusos. Ovario súpero bicarpelar.

Fruto capsular de 7 a $10 \mathrm{~cm}$ de longitud, con numerosas semillas reniformes, agrietadas.

Nativa de Sudamérica.

\section{Familia Sterculiaceae}

Braclychiton populnets (Schott \&Endl.) R.Br. "Peral japonés"

Árbol de porte mediano, tronco grueso, copa

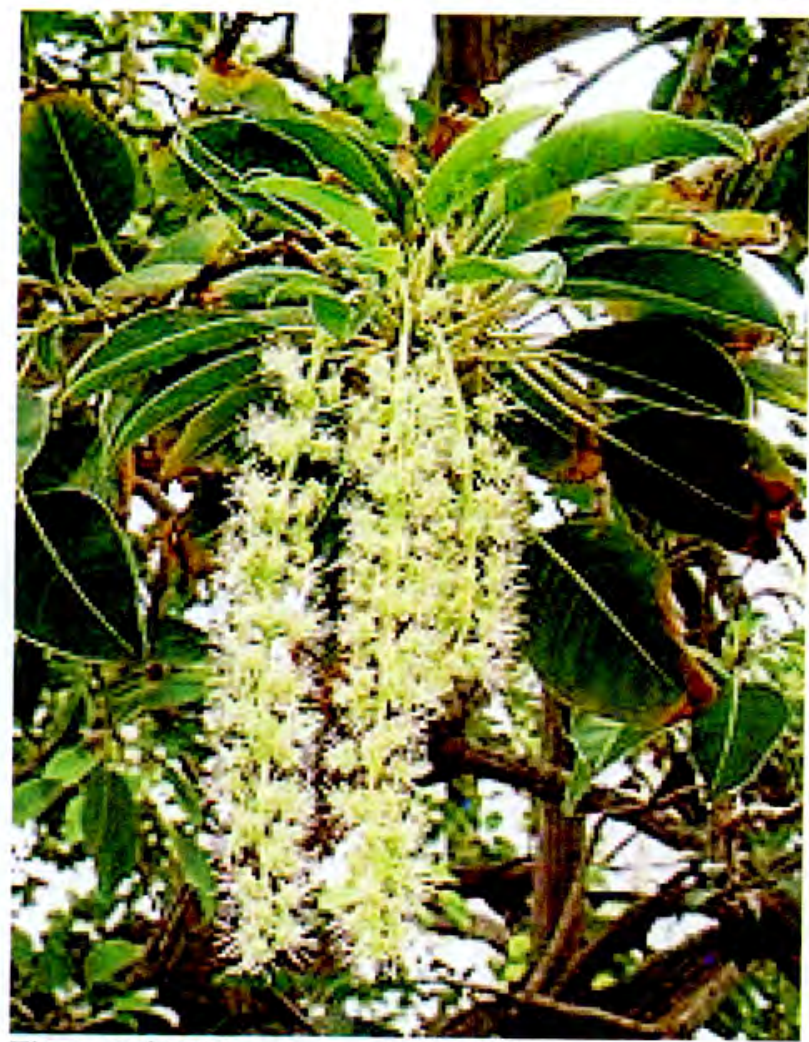

Figura N02.Phytolacca dioica " Ombú" 
frondosa.

Hojas perennifolias simples, alternas, pecíolos largos y delgados, verde brillantes, aovado lanceoladas, de 5 a $10 \mathrm{~cm}$ de longitud.

Flores blanco amarillentas, acampanadas, con manchas de color rojizo internamente, de $1 \mathrm{~cm}$ de longitud, reunidas en panículas, en las axilas de las hojas superiores.

Fruto en folículo de 5 a $7 \mathrm{~cm}$ de longitud, leñoso, de color negro en la madurez, tapizado internamente de pelos rígidos.

Semillas amarillas cubiertas de pelos.

Florece en primavera. Se reproduce por semillas y gajos.

Nativa de Australia.

Es una especie rara. No se le ve en otras áreas verdes de la ciudad.

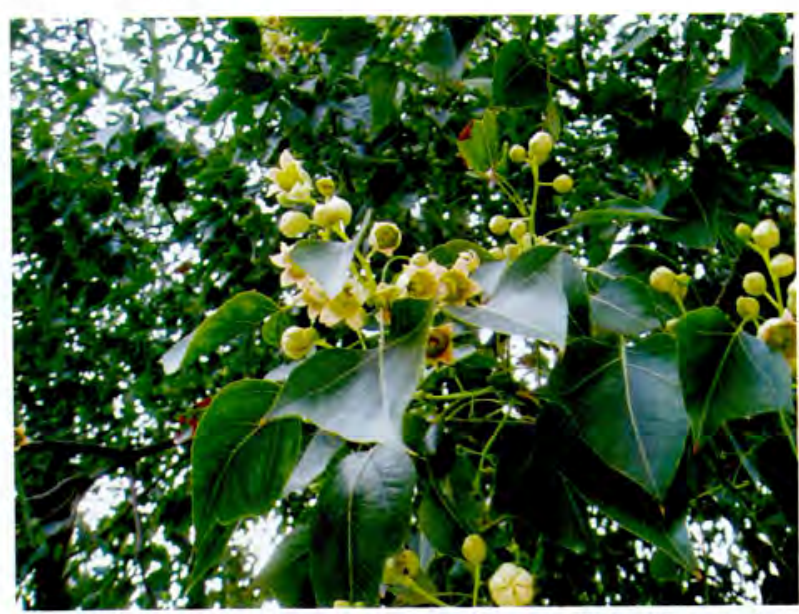

Figura $N^{\circ} 03$. Brachychiton populneus "Peral Japonés"

\section{b.2. Clase Liliopsida}

\section{Familia Arecaceae}

Jubaea spectabilis H.B.K. "Palmera Coquito"

Palmera de estípite robusto, ensanchado en su mitad inferior y liso, de 0,70 a 2 m de diámetro.

Hojas pinnadas, con el pecíolo inerme.
Flores reunidas en espádices interfoliares, de 1 a $1,20 \mathrm{~m}$ de longitud, protegidos por dos espatas desiguales.

Flores diclino monoicas. Tiene seis tépalos. Estambres numerosos en las flores masculinas y ovario trilocular en las flores femeninas.

Fruto drupáceo ovoide.

Oriunda de América del Sur.

Phoenix canariensis Hort.'Palmera datilera ornamental"

Palmera dioica. Estípite robusto, está cubierto por cicatrices foliares, de 10 a $20 \mathrm{~m}$ de altura.

Hojas pinnadas, de 4 a $5 \mathrm{~m}$ de longitud.

Espádices extendidas o péndulas interfoliáceos. Ofrece flores con 6 tépalos. Tiene generalmente 6 estambres en las flores masculinas, y flores femeninas con ovario súpero tricarpelar. longitud.

Fruto: Drupa amarilla, oblonga, de 2 a $2,5 \mathrm{~cm}$ de

Originaria de Islas Canarias.

En nuestra ciudad es la palmera más abundante.

\section{CONCLUSIONES}

Se ha realizado el estudio morfotaxonómico de 19 especies ornamentales, tanto arbóreas como arbustivas, todas ellas ubicadas en la primera cuadra de la Av. Bolognesi.

De las 19 especies estudiadas, dos pertenecen a la División Pinophyta, y 17 a la División Magnoliophyta.

La familia con mayor número de especies es la familia Fagaceae.

\section{REFERENCIAS BIBLIOGRÁFICAS}

FERN ÁNDEZ DE CÓRDOVA G. (2003) Crónicas del Reino de Ancat. Tacna. Perí.

KRAMER, J.( 1981). Flowering bouseplants.Salamander Book.London.

PIZETTIM. 1985. Plantas de interior: Barcelona-España. POKORNY J. 1973. Trees, leaves, bark and fruits. PragaChecoslovaquia.

SOLARI S., ROMAN F., LERNER T. 2008. Arboles de Lima. Lima-Perí.

\section{Correspondencia:}

Rosario Zegarra Zegarra: rosariozegarra13@hotmail.com
Fecha de Recepción: 30/05/2014

Fecha de Aceptación: 25/06/2014 